Imagine People Like Us:

Imagined Intergroup Contact Promotes Support for Human Rights through Increased Humanization

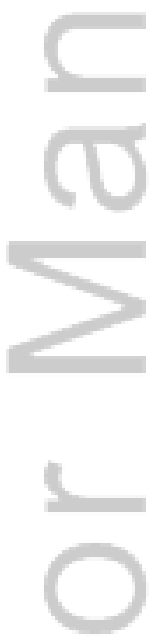

Word Count: 8653

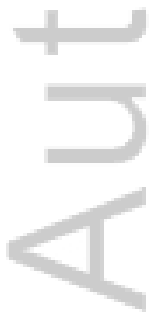

This is the author manuscript accepted for publication and has undergone full peer review but has not been through the copyediting, typesetting, pagination and proofreading process, which may lead to differences between this version and the Version of Record. Please cite this article as doi: $10.1002 /$ ejsp.2282

This article is protected by copyright. All rights reserved. 


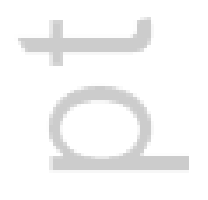

\begin{abstract}
Dehumanization concerns the denial of others' human uniqueness (animalistic dehumanization) or human nature (mechanistic dehumanization). Imagined intergroup contact has been suggested to be an effective technique for reducing dehumanization. We examined whether this intervention might primarily work by increasing the type of humanness the group specifically lacks. Study 1 revealed that after imagining contact with an animalized outgroup (i.e., Gypsy people), participants attributed higher levels of human uniqueness. Study 2 replicated this finding, eliminating improved intergroup attitudes as an alternative explanation. Further, it demonstrated that imagined contact increased support for human rights, and that this was mediated by increased adscription of human uniqueness. Study 3 confirmed previous evidence by showing that after imagining contact with a mechanized outgroup (i.e., Japanese people), participants attributed higher levels of human nature that explains support for human rights. Overall, imagined contact specifically works at increasing the type of humanness the group is typically denied. (150 words)

KEYWORDS: Dehumanization, Infrahumanization, Imagined Contact, Intergroup Relations
\end{abstract}




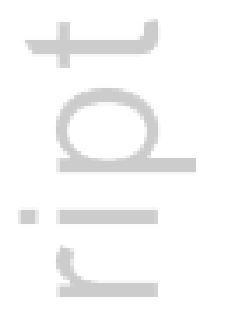

It is well established that people dislike and hold negative attitudes towards outgroups, particularly ethnic minorities (Allport, 1954). However, negative attitudes towards others extend beyond antipathy to encompass dehumanization - seeing others as less than fully human. In particular, two different but equally troublesome types of dehumanization has been identified (Haslam, 2006; Haslam \& Loughnan, 2014). The denial of human uniqueness leads us to perceive and treat others as animals, whereas the denial of human nature leads us to see others to robots; both serve to justify mistreatment. Despite increased recognition of the importance of dehumanization (cf. Haslam, 2006; Leyens, Demoulin, Vaes, Gaunt, \& Paladino, 2007) and its negative consequences (Greitermeyer, \& McLachie, 2011; Vaes, Paladino, Castelli, Leyens \& Giovanazzi, 2003), to date little research has examined ways of reducing dehumanization towards others. The literature on prejudice reduction has recently showed in a sample of children that imagining positive intergroup contact can reduce dehumanization (Vezzali, Capozza, Giovannini \&, Stathi 2012; Vezzali, Capozza, Stathi, \& Giovannini, 2011). In the current paper, we will examine whether imagined contact serves to increase the specific type of humanness the group target is denied and whether this in turn would explain support for the group target' human rights. 


\section{Outgroup Dehumanization}

People have a tendency to believe that their ingroup possesses more humanness than other groups (Leyens et al., 2000; 2001). Importantly, these effects occur in everyday intergroup relations, not only against the backdrop of extreme violence (Kelman, 1973; Struch \& Schwartz, 1989). In a series of studies, Leyens and colleagues demonstrated that secondary or uniquely human emotions (e.g., admiration, regret) are attributed more to ingroup than outgroup members, and there was no difference in the attribution of primary emotions shared between humans and animals (e.g., anger, excitement). Since this finding, convergent evidence for infrahumanization has shown that the outgroup is implicitly seen as more animal-like than the ingroup because the former is perceived to be able to express uniquely human emotions to a lower extent compared to the latter (Viki et al., 2006).

Haslam (2006) expanded this model by distinguishing the denial of uniquely human characteristics (not only emotions but also traits) that leads to the association with animals (animalistic dehumanization) from the denial of human nature characteristics that leads to association to robots (mechanistic dehumanization/objectification; cf. Heflick \& Goldenberg, 2009; Loughnan \& Haslam, 2007; Loughnan, Haslam, \& Kashima, 2009).

In a series of studies, Haslam and colleagues established that human uniqueness and human nature are important and distinct dimensions of social perception at both the interpersonal (Bastian \& Haslam, 2010; Haslam et al., 2005; Haslam \& Bain, 2007; Loughnan et al., 2010) and the intergroup level (Bain et al., 2009; Saminaden, Loughnan, \& Haslam, 2010). Traits that embody human uniqueness are seen as late to develop and believed to differ across cultures, whereas those 
that embody human nature are seen as essence-like, universal, and emotion related (Haslam et al. 2005). The understandings of these two sets of characteristics are highly convergent across cultures (Bain et al. 2012, Park et al. 2012). Independent of the type of dehumanization, a decade of research has revealed that this pervasive and persistent tendency to perceive others as less human than us explains both extreme and everyday negative attitudes and behaviours (Haslam \& Loughnan, 2014).

The link between dehumanization and negative treatment has been robustly established in terms of increased anti-sociality and reduced pro-sociality. The role of dehumanization on violence, and aggression was emphasized in the early writings of Kelman and Staub on war and genocide, and early work by Bandura and colleagues (1996) firmly established that the dehumanization of victims disinhibits violent actions. Whereas this evidence was at the intergroup level, further studies have shown the same effects at the interpersonal level (e.g., Bastian, Jetten, \& Radke, 2012; Greitermeyer \& McLatchie, 2011). Moreover, it reduces the extent to which people want to help outgroup members (Cuddy, Rock \& Norton, 2007), express solidarity (Vaes et al., 2003), and make reparations for prior injustices (Tam et al., 2007).

While a large body of research has now demonstrated the widespread occurrence of dehumanization and explored its consequences for social behavior, relatively little is known about how dehumanization can be reduced and humanization of the outgroup can be promoted (Haslam \& Loughnan, 2014). One potential mechanism is intergroup contact, which is associated with less dehumanizing perceptions of the contacted outgroup (Brown, Eller, Leeds, \& Stace, 2007; Capozza, Trifiletti, Vezzali, \& Favara, 2013; Tam et al., 2007).

\section{Imagined Contact}


In the field of intergroup relations, one of the most reliable - if not always strongest effects shown is that contact between members of different groups attenuates intergroup discrimination leading to favourable intergroup attitudes (Brown \& Hewstone, 2005; Lemmer \& Wagner, 2015). However, direct intergroup contact has practical limitations (Crisp, Stathi, Turner, \& Husnu, 2009). These include the difficulty of engaging in direct contact in segregated settings (Husnu \& Crisp, 2010a), the prevalence of negative contact in hostile intergroup settings (Paolini, Harwood, \& Rubin, 2010), and the influence of anxiety on direct contact (Greenland \& Brown, 1999). Recent research has shown that indirect forms of intergroup contact may overcome these issues. Of these indirect forms imagined contact, "the mental simulation of a social interaction with a member or members of an outgroup category" (Crisp \& Turner, 2009, p.234) can evoke cognitive and behavioural effects similar to those experienced in the context itself (Dadds, Bovbjerg, Redd, \& Cutmore, 1997; Garcia, Weaver, Moskowitz, \& Darley, 2002). Research on mental imagery has shown that it fosters more positive intentions to engage in outgroup contact (Husnu \& Crisp, 2010a, 2010b), increases self-efficacy concerning future outgroup contact (Stathi, Crisp, \& Hogg, 2011), and facilitates outgroup trust (Pagotto, Visintin, De Iorio, \& Voci, 2012; Vezzali, Capozza, Stathi, \& Giovannini, 2012). In addition to leading to improved attitudes, imagined contact reduces intergroup anxiety (Birtel \& Crisp, 2012; Husnu \& Crisp, 2010a; Turner et al., 2007; West, Holmes, \& Hewstone, 2011), negative stereotypes (Brambilla, Ravenna, \& Hewstone, 2012; Cameron, Rutland, Turner, Holman-Nicolas, \& Powell, 2011; Stathi, Tsantila, \& Crisp, 2012), and stereotype threat (Abrams et al., 2009). Imagined contact appears to be an effective mechanism for promoting positive intergroup relations and even preventing subtle forms of bias such as implicit prejudice 
(Turner \& Crisp, 2010). The current study will extend this literature by examining how imagined contact reduces intergroup dehumanization.

To date, evidence showed that after a 3-week long intervention where elementary school children were involved in imagining meeting an unknown immigrant peer in various situations, they displayed more trust, reduced infrahumanization, and enhanced future contact intentions toward immigrants compared to children in a control condition (Vezzali et al., 2012; Vezzali et al., 2011). This demonstrates that dehumanization is malleable to an imagined contact intervention. However, this research also presents shortcomings. First, the participants were schoolchildren and therefore it is not clearly generalizable to a broader population; second, we do not know whether imagined contact influences both forms of dehumanization; third, the implications of this reduced dehumanization on intergroup behavioural intentions are not yet been examined.

\section{Overview and predictions}

The current research has three aims. First, it investigates whether imagined contact with an outgroup member would increase the attribution of the specific type of humanness that outgroup is denied (human nature or human uniqueness). Second, it examines whether imagined contact with an outgroup member increases support for that outgroup' human rights. Third, the present research tests the mediating role of the ascription of humanness to outgroup members in the effects of imagined contact on support for outgroup members' human rights. Put simply, it examines whether increasing the groups humanness leads people to see them as more deserving of human rights.

To these aims, we consider two dehumanized ethnic minorities in Western countries; Gypsies and Japanese people. If Gypsies are seen as more animalistic than the ingroup in Western 
countries (Pérez, Chulvi, Alonso, 2001; Vaes \& Paladino, 2010), we can expect that imagined contact should lead to an increase in the human uniqueness traits they are routinely denied (Studies 1 and 2). Similarly, imagined interactions with a Gypsy person should reduce the infrahumanization bias or the tendency to attribute them less ability to feel uniquely human emotions. We also examined whether imagined contact will lead to increased support for Gypsies' rights, and whether this support will be explained by Gypsies humanization, in terms of increased attribution of uniquely human traits. Importantly, we expected the benefits of humanization to occur independently of improved behavioural intentions.

Furthermore, if Japanese people are seen as more robot-like than the ingroup in Western countries (Andrighetto et al., 2014), we expected that imagined contact with a Japanese person should lead to an increase of human nature traits this outgroup target is routinely denied (Study 3). We further examine the mediating role of humanization, in terms of attribution of human nature traits to Japanese people and the effect of imagined contact on support for their rights.

\section{Study 1}

Study 1 examined whether imagined contact would enhance humanization of a highly discriminated and threatening group as Gypsies are perceived to be in Western countries (Pérez et al., 2001; Vaes \& Paladino, 2010). Roma or Traveller Gypsy people ${ }^{1}$ continue to face widespread, widely endorsed discrimination. In surveys, one third of Britons admitted to being prejudiced against Gypsies (Stonewall, 2003), one of the few ethnic groups with which people typically report no contact (Valentine \& McDonald, 2004). Historically, Gypsies have been subjected to extreme intergroup violence (e.g., genocide; Kelso, 1999), and they continue to face serious disadvantage. A 
recent European Commission report revealed that $42 \%$ of Roma children complete primary school compared to the European average of $97.5 \%$ (EU report, 2011). Adult life expectancy is ten years lower than non-Roma Europeans. In Britain, Travelers are largely segregated, marginalized, and denied equal opportunities in health and education (Commission for Racial Equality, 2004). There are numerous examples of sedentary communities mobilizing to oppose Gypsies and Gypsy communities (Brent, 2004; Twelvetrees, 2002). Chulvi and Pérez (2003) argued that Gypsies are situated outside the human species, somewhere between animals and humans. Correlational and experimental research has confirmed that Gypsies are attributed more animal than human traits in Spain, Romania, and Britain (Pérez et al., 2001). This finding has been extended to the underattribution of human characteristics (Marcu \& Chryssochoou, 2005). Consistent with this research Vaes and Paladino (2010) found that Gypsies were amongst the most dehumanized ethnic groups in Italy. In sum, Gypsies may be seen as amongst the least human ethnic groups in Europe.

Given that Gypsies are denied the specific type of uniquely human characteristics by being associated more with animals than human beings, we hypothesized that imagining a positive interaction with a Gypsy will increase the attribution of human uniqueness to this group. Finally, we predicted that imagining contact with a Gypsy can enhance support for human rights of this group, an effect mediated by humanization through increased uniquely human emotions.

\section{Method}

\section{Participants}

Ninety-one British undergraduate students $\left(\mathrm{M}_{\mathrm{age}}=19.71, \mathrm{SD}=3.41 ; 76.9 \%\right.$ women $)$ participated in exchange for course credit. 


\section{Materials and Procedure}

After being greeted by an experimenter and filling out the consent form, participants were randomly allocated to either the imagined contact or control condition. Participants assigned to the imagined contact condition were told: 'Imagine yourself meeting a Gypsy person for the first time. Imagine that the interaction is relaxed, positive and comfortable'. Participants assigned to the control condition typically used (cf. Turner, Crisp, \& Lambert, 2007, page 431): 'We would like you to take a minute to imagine yourself watching a landscape for the first time. Imagine that the view is relaxing, positive and comfortable.' In both conditions, participants were given one minute to imagine the scene. Participants in both conditions were then instructed to summarize what they had imagined in a few sentences (cf. Miles \& Crisp, 2014).

Following the imagination task, participants completed a series of ratings. To assess dehumanization, participants rated the extent to which a Gypsy possesses a series of 21 personality traits sampled from previous dehumanization research (Haslam et al., 2005; Loughnan et al., 2010). Each trait was rated from 1 (much less than average population) to 7 (much more than average population) with midpoint described as meaning that the target possesses the trait (neither less nor more than the average population) (see also Prati, Vasiljevic, Crisp, \& Rubini, 2015). To assess infrahumanization, twelve emotion words were sampled from Demoulin et al. (2004): primary emotions $(\alpha=.71$; positive: excitement, surprise, attraction, $\alpha=.73$; negative: anger, sadness, fright, $\alpha=.65$ ) and secondary emotions ( $\alpha=.73$; positive: admiration, hope, empathy, $\alpha=.71$; negative: melancholy, regret, contempt, $\alpha=.69$ ). Participants rated the extent to which each emotion was experienced by Gypsies from 1 (not at all) to 7 (very much) ${ }^{2}$ After completing the 
dependent measures, participants provided demographic information. To allow the construction of humanness scores, participants were asked to indicate the extent to which they considered each of the 21 personality characteristics i) part of human nature and ii) unique to humans from 1 (not at all) to 7 (very much). At the end, they were asked to share their thoughts about the study (e.g., what they thought the study was about), and then were fully debriefed about the nature of the study. There were no additional measures, manipulations, or exclusions in this study besides what was reported here. Data collection did not continue after these analyses were conducted.

\section{Results}

In order to determine the traits which best reflected human nature and human uniqueness, we examined participants rating of the traits after the main task. From this we selected the seven most representative human nature characteristics $(\alpha=.72$; positive: curious, sociable, cautious, $\alpha=$ .65; negative: selfish, ambitious, defensive, aggressive, $\alpha=.79$ ) and the seven most representative uniquely human characteristics ( $\alpha=.77$; positive: idealistic, broadminded, polite, artistic, $\alpha=.81$; negative: ambitious, envious, conventional, $\alpha=.74$ ).

To examine whether imagined contact might decrease dehumanization, we measured attributions of human nature and human uniqueness. Given that Gypsies tend to be seen as animallike (Perez et al., 2001), we hypothesized increased human uniqueness attributions. A 2 (condition: imagined contact, control) $\times 2$ (trait valence: positive, negative) $\times 2$ (trait type: uniquely human, human nature) mixed model ANOVA was conducted on human traits, with repeated measures on the last factors. Results revealed a main effect of condition, $F(1,89)=6.418, p=.013, \eta^{2}=.067$, showing that overall human traits were attributed to a greater extent after imagining contact $(M=$ 
$4.42, S D=0.07)$ compared to control condition $(M=4.16, S D=0.07)$. No other main effect was significant, $F<2.612, p>.110$. The analysis also yielded a two-way interaction between trait type and condition, $F(1,89)=27.133, p=.001, \eta^{2}=.234$. As expected, participants in the imagined contact condition attributed human uniqueness traits to Gypsies to a greater extent compared to those in control condition, $F(1,91)=17.503, p=.001, \eta^{2}=.164$. No differences emerged for human nature, $F(1,91)=0.126, p=.724, \eta^{2}=.001$. In short, imagined contact served to increase attributions of the type of humanness Gypsies are typically denied. Table 1 provides means, standard deviations and intercorrelations for the measures of the study.

To examine whether imagined contact can reduce infrahumanization, we measured the attribution of primary and secondary emotions. A 2 (condition: imagined contact, control) $\times 2$ (emotion valence: positive, negative) $\times 2$ (emotion type: secondary, primary) mixed model ANOVA was conducted on emotions, with repeated measures on the last factors. Results revealed that Gypsies were attributed overall emotions to a greater extent in the imagined contact $(M=4.35$, $S D=0.08)$ compared to control condition $(M=3.85, S D=0.09), F(1,89)=16.959, p=.001, \eta^{2}=$ .160. Although the effect was clearly larger for secondary emotions (Cohen's $d^{\text {se }}=0.79$ vs. $d^{\text {pe }}=$ 0.49), the simultaneous increase of both suggests that imagined contact is making the emotional life of the Gypsies more accessible to the participant. In line with previous research, overall participants attributed primary emotions $(M=4.54, S D=0.07)$ to a greater extent compared to secondary emotions $(M=3.66, S D=0.09), F(1,89)=87.506, p=.001, \eta^{2}=.496$ to the outgroup members Gypsies. No other effect was significant, $F<3.047, p>.084$. There was also a two-way interaction between valence and emotion type, $F(1,89)=36.920, p=.001, \eta^{2}=.293$. Analysis of 
simple main effects showed that overall participants attributed more positive primary $(M=4.93, S D$ $=0.10)$ compared to positive secondary emotions $(M=3.37, S D=0.13, p=.001)$ whereas there was no significant difference between negative primary $(M=3.96, S D=0.09)$ and negative secondary emotions $(M=4.16, S D=0.10, p=.077)$.

\section{Discussion}

Study 1 largely supported the hypothesis that imagined contact with Gypsies that are usually associated to animals, (Pérez et al., 2001) increases the adscription to them of attributes that distinguish human beings from animals, that are uniquely human characteristics. This study is the first to use imagined contact with adults and show that it promotes outgroup members humanization. Importantly, imagined contact had an effect in the domain which Gypsies are stereotyped as most deficient, human uniqueness. Overall, the results confirmed our predictions of the humanizing effects of imagined contact using two different measures, uniquely human emotions and uniquely human traits.

\section{Study 2}

Study 2 had three aims. First, we wanted to replicate the effect of imagined contact with a Gypsy on the attribution of human uniqueness to the group of Gypsies. Second, we examined whether the results obtained in Study 1 were reducible to improved behavioural intentions. Third, we investigated the potential consequences of promoting Gypsies' human uniqueness. One important consequence would be increased support for their human rights. Human rights are - by definition - extended to human groups, and by increasing Gypsies human uniqueness, imagined contact may serve to increase support for these rights. 


\section{Method}

\section{Participants}

Fifty-three British undergraduate students $\left(\mathrm{M}_{\mathrm{age}}=19.98, S D=2.51 ; 66 \%\right.$ women $)$ received course credit for their participation.

\section{Materials and Procedure}

The procedure was the similar to Study 1 . The same manipulation was employed, requiring participants to imagine an interaction with a Gypsy or a pleasant landscape. As in the previous study, participants first rated a Gypsy person in comparison to the average person on a set of 21 personality traits. Subsequently they rated the extent to which a Gypsy person possesses primary ( $\alpha=.57$, positive $\alpha=.66$, negative $\alpha=.70$ ) and secondary emotions ( $\alpha=.62$, positive $\alpha=.67$, negative $\alpha=.71)$.

To explore the role of attitude change, we measured participants' desire to behave in a particular way toward the target (Mackie, Devos, \& Smith, 2000). Negative behavioural intentions towards Gypsies was measured by three items: How much do you want to 'Oppose with them' 'Confront them, 'Argue with them' $(\alpha=.87)$. Positive behavioural intentions towards Gypsies was measured by three items: How much do you want to 'talk with them', 'spend time with them', 'find out more about them' $(\alpha=.89)$. Participants responded to all items on a 7-point scale $(1=$ not at all; $7=$ very $m u c h$.

To examine the potential impact of imagined contact on the treatment, participants were asked about Gypsy human rights. Participants were asked to indicate to what extent they agree $(1=$ not at all, $10=$ very much) on four human rights for Gypsy people. They were asked to rate the 
extent to which Gypsy people have the right to 'freedom of movement and residence within the borders of each state'; '...codify, standardize, preserve, develop and promote their language (Shelta), without induced or forced interference'; '... a standard of living adequate for their health and well-being, and the right to social security in the event of unemployment, sickness, disability, widowhood, old age or other lack of livelihood in circumstances beyond his control'; '... social security and is entitled to realization, through national effort and international co-operation' $(\alpha=$ .79). After providing demographic information, participants were then thanked and debriefed. There were no additional measures, manipulations, or exclusions in this study besides what was reported here. Data collection did not continue after these analyses were conducted.

\section{Results}

To create measures of human nature and human uniqueness, we used the same traits as in Study 1 (human nature: $\alpha=.65$, positive $\alpha=.72$, negative $\alpha=.63$; uniquely human: $\alpha=.85$, positive $\alpha=.81$, negative $\alpha=.79$ ). Consistent with Study 1, a 2 (condition: imagined contact, control $) \times 2$ (trait valence: positive, negative) $\times 2$ (trait type: uniquely human, human nature) mixed model ANOVA with repeated measures on the last factors was conducted. Results showed that overall human traits were attributed to Gypsies to a greater extent by participants in imagined contact $(M=4.56, S D=0.16)$ compared to those in control condition $(M=3.85, S D=0.16), F(1$, $51)=9.717, p=.003, \eta^{2}=.160$. Positive human traits $(M=4.42, S D=0.13)$ were attributed to the target to a greater extent compared to negative human traits $(M=3.99, S D=0.12), F(1,51)=$ 20.087, $p=.001, \eta^{2}=.283$. A two-way interaction between trait type and condition $F(1,51)=$ 4.192, $p=.045, \eta^{2}=.076$ was also found. Analysis of simple main effects confirmed previous 
results, showing that uniquely human traits were attributed to Gypsies to a greater extent after imagining contact than control condition, $F(1,51)=10.151, p=.002, \eta^{2}=.166$. Contrary to Study 1, also human nature traits were attributed to Gypsies to a greater extent in imagined contact compared to control conditions, $F(1,51)=4.699, p=.035, \eta^{2}=.084$. However, the effect was substantially larger for human uniqueness (Cohen's $d^{\text {hu }}=0.89 \mathrm{v} \mathrm{d}^{\text {hn }}=0.61$ ). Table 2 provides means, standard deviations, and intercorrelations for the measures of this study.

A 2 (condition: imagined contact, control) $\times 2$ (emotion valence: positive, negative) $\times 2$ (emotion type: secondary, primary) mixed model ANOVA was conducted on emotions, with repeated measures on the last factors. As in Study 1, results revealed that overall emotions were attributed to Gypsies to a greater extent in the imagined contact $(M=4.74, S D=0.13)$ compared to control condition $(M=4.35, S D=0.13), F(1,51)=4.503, p=.039, \eta^{2}=.081$. Positive emotions $(M$ $=4.68, S D=0.10)$ were attributed to the target to a greater extent compared to negative emotions $(M=4.41, S D=0.11), F(1,51)=6.570, p=.013, \eta^{2}=.114$. Secondary emotions $(M=4.78, S D=$ $0.11)$ were attributed to a greater extent compared to primary emotions $(M=4.31, S D=0.09), F(1$, $51)=21.910, p=.001, \eta^{2}=.301$. A two-way interaction between condition and emotion type, $F(1$, $51)=8.927, p=.004, \eta^{2}=.149$ and a two-way interaction between emotion valence and emotion type, $F(1,51)=16.312, p=.001, \eta^{2}=.242$ were also found. Analysis of simple main effects showed that secondary emotions were attributed to Gypsies to a greater extent by participants in imagined contact compared to those in control condition, $p=.022$, whereas no difference was found in attribution of primary emotions, $p=.672$. Moreover, negative secondary emotions $(M=4.88, S D$ $=0.13)$ were attributed to a greater extent compared to negative primary emotions $(M=3.95, S D=$ 
$0.15, p=.001)$, whereas there was no significant difference between positive secondary $(M=4.69$, $S D=0.11)$ and primary $(M=4.66, S D=0.11, p=.772)$ emotions.

Participants after imagining contact reported less negative behavioural intentions towards Gypsies compared to those in control condition, $F(1,51)=4.811, p=.033, \eta^{2}=.086$, whereas there was no significant difference in positive behavioural intentions scores between imagined and control conditions, $F(1,51)=0.001, p=.974, \eta^{2}<.001$.

In short, the results of this study largely replicated those of Study 1. It revealed that imagined contact increases attributions of human uniqueness, human nature, and secondary emotions, all indicative of reduced dehumanization.

Study 2 additionally sought to examine whether imagined contact changed beliefs about Gypsy human rights. As predicted, people in the imagined contact condition reported increased endorsement of Gypsies human rights, $F(1,51)=4.044, p=.049, \eta^{2}=.073$.

To examine whether changes in support for Gypsy rights might be explained by reduced dehumanization, we conducted a mediation analysis. Since imagined contact also improved intergroup behavioural intentions via decreased negative behavioural intentions, we entered negative behavioural intentions as a covariate. We employed uniquely human traits ratings as our mediator, since they are the correspondent measure of animalistic dehumanization (cf. Haslam, 2006). As showed in Figure 1, condition predicted human rights. When both condition and uniquely human traits were entered simultaneously, condition became non-significant and uniquely human traits was a significant predictor. Following the protocols of Preacher and Hayes (2008), we conducted a bootstrapped measure of indirect effects, revealing a significant meditation as indicated 
by a $95 \%$ confidence interval that does not include zero $(\mathrm{CI}=0.11 ; 0.83)$. Changes in support for Gypsy human rights can be explained by changes in attributions of humanness. Further, this effect holds when controlling for improved behavioural intentions.

\section{Discussion}

Overall, Study 2 confirmed the humanizing effect of imagined contact. In particular, people who imagined interacting with a Gypsy increased attribution of uniquely human traits and secondary or uniquely human emotions. In line with previous research (Turner et al., 2007), we found that imagined contact improved intergroup behavioural intentions. Further, not only did imagined contact promote Gypsies’ human rights but this effect was mediated by increased attribution of uniquely human characteristics even after controlling for improved behavioural intentions. To further test the strength of imagined contact in increasing the specific type of humanness the target is routinely denied, we investigated the effect of this strategy in a group that is usually perceived to lack human nature traits, such as Japanese people in Western countries.

\section{Study 3}

Study 3 examined whether imagined contact would increase the type of humanness is usually denied to Japanese people, that is human nature. According to the Stereotype Content Model (Fiske, Cuddy, Glick, \& Xu, 2002), Asians are envied groups respected as competent but disliked as lacking warmth in Western countries (Lin, Kwan, Cheung, Fiske, 2005). A review of Asian American stereotypes over time further demonstrates that in Western countries the dominant group tends to characterize Asians along the lines of competence and unsociability. In the classic Katz and Braly (1933) stereotyping study, Japanese people were seen as intelligent, industrious, 
progressive, and shrewd (i.e., competent) but shy and quiet (i.e., unsociable). A cross-cultural study (Bain, Park, Kwok, \& Haslam, 2009) revealed that the two forms of dehumanization reflect stereotypes. In particular, the cultural stereotype of Japanese people, portraying them as having high self-control, low warmth, and high intelligence, led Anglo-Australians to deny them human nature and to subtly associate them with automata. To further support this evidence, a recent research showed that Italian people attributed low human nature (dehumanized as automata) to Japanese people and this explains decreased willingness to help them, even when controlling for attitudes (Andrighetto et al., 2014).

If Japanese people are seen as more mechanistic than the ingroup in Western countries, we expected that imagined contact should lead to an increase in the type of humanness they are routinely denied (i.e., human nature). Furthermore, imagined interactions with a Japanese person should increase the tendency to support their human rights of. Finally, increased human nature should mediate the effect of imagined contact on support to Japanese people human rights.

\section{Participants}

\section{Method}

Seventy people $\left(\mathrm{M}_{\mathrm{age}}=31.06, S D=3.85 ; 58,6 \%\right.$ women $)$ living in Italy $(100 \%$ reported having an Italian national identity) participated in an online survey in exchange for monetary payment.

\section{Materials and Procedure}

The procedure was the similar to the one of previous studies except for the group target and the use of on-line survey. Participants were asked to imagine an interaction with a Japanese person (imagined contact condition) or a pleasant landscape (control condition). As in the previous studies, 
participants first rated a Japanese person in comparison to the average person on a set of 14 personality traits (human nature: $\alpha=.73$; human uniqueness: $\alpha=.75$ ) as in the previous study. Subsequently they rated the extent to which a Japanese person possesses primary $(\alpha=.65$; positive: $\alpha=.71$, negative: $\alpha=.78$ ) and secondary emotions ( $\alpha=.67$; positive: $\alpha=.73$, negative: $\alpha=.69$ ). Finally, participants were asked to indicate to what extent they agree $(1=$ not at all, $10=$ very much) on four human rights for Japanese people. They were asked to rate the extent to which Japanese people have the right to 'work no more than 8 hours per day'; 'marry the woman/man who they want'; 'to health and well-being in the workplace', 'to social security in the event of unemployment, sickness, disability, widowhood, old age or other lack of livelihood in circumstances beyond his control' $(\alpha=.65)^{3}$. After completing the dependent measures, participants provided demographic information. At the end of the on-line questionnaire, they could read a brief explanation of what the study was about and were encouraged to contact the first author id they have any questions. There were no additional measures, manipulations, or exclusions in this study besides what was reported here. Data collection did not continue after these analyses were conducted.

\section{Results}

To examine whether imagined contact would decrease dehumanization of Japanese people, we measured attributions of human nature and human uniqueness. Given that Japanese people tend to be seen as robot-like (Bain et al., 2009), we hypothesized increased human nature attributions. A 2 (condition: imagined contact, control) $\times 2$ (trait valence: positive, negative $) \times 2$ (trait type: uniquely human, human nature) mixed model ANOVA was conducted on human traits, with 
repeated measures on the last factors. Results revealed a main effect of condition, $F(1,68)=$ 30.382, $p=.001, \eta^{2}=.309$, showing that overall human traits were attributed to a greater extent after imagining contact $(M=4.45, S D=0.11)$ compared to control condition $(M=3.65, S D=0.10)$. A main effect of trait type, $F(1,68)=7.363, p=.007, \eta^{2}=.101$ was also found. Uniquely human traits $(M=4.26, S D=0.11)$ were attributed to the target to a greater extent compared to human nature traits $(M=3.85, S D=0.09)$. There was no significant effect of valence, $F(1,68)=0.490, p=$ $.486, \eta^{2}=.007$. The analysis also yielded a two-way interaction between trait type and condition, $F(1,68)=12.033, p=.001, \eta^{2}=.150$. As expected, participants in the imagined contact condition attributed human nature traits to Japanese people to a greater extent compared to those in control condition, $p=.001$. No differences emerged for human uniqueness, $p=.226$. In short, imagined contact served to increase attributions of the type of humanness Japanese people are typically denied. Table 3 provides means, standard deviations, and intercorrelations for the measures of this study. Moreover, in the control condition uniquely human traits were attributed to the target to a greater extent compared to human nature traits $p=.001$, whereas no significant difference was found between human nature and uniquely human traits in the imagined contact condition, $p=.629$.

A 2 (condition: imagined contact, control) $\times 2$ (emotion valence: positive, negative $) \times 2$ (emotion type: secondary, primary) mixed model ANOVA was conducted on emotions, with repeated measures on the last factors. Results revealed that Japanese people were attributed overall emotions to a greater extent in the imagined contact $(M=4.36, S D=0.12)$ compared to control condition $(M=3.98, S D=0.11), F(1,68)=5.456, p=.022, \eta^{2}=.074$. Although the effect was clearly larger for primary emotions (Cohen's $\mathrm{d}_{\mathrm{se}}=0.22 v s . \mathrm{d}_{\mathrm{pe}}=0.48$ ). As before, the simultaneous 
increase of both suggests that imagined contact is making the emotional life of the Japanese people more accessible to the participant. No other effect was significant, $F<1.853, p>.178$. There was also a two-way interaction between valence and emotion type, $F(1,68)=4.018, p=.048, \eta^{2}=$ .056. Analysis of simple main effects showed that participants attributed positive emotions to Japanese people after imagining contact compared to control condition $p=.009$, whereas there was no significant difference of attribution of negative emotions between conditions, $p=.136$. Moreover, in imagined contact condition positive emotions were attributed to Japanese people to a greater extent compared to negative ones, $p=.024$, whereas no significant difference was found between positive and negative emotions in control condition, $p=.641$.

Finally, as predicted, people in the imagined contact condition reported increased endorsement of Japanese people's human rights, $F(1,68)=18.986, p=.001, \eta^{2}=.218$. As in Study 2, we conducted a mediation analysis to examine whether changes in support for Japanese people's human rights might be explained by increased attribution of human nature traits. As showed in Figure 2, condition predicted human rights. When both condition and human nature were entered simultaneously, condition became non-significant and human nature was a significant predictor. This result was confirmed by a $95 \%$ confidence interval that does not include zero $(\mathrm{CI}=0.04 ; 1.22)$. Changes in support for Japanese people's human rights can be explained by changes in attributions of human nature traits.

\section{Discussion}

Study 3 confirmed previous studies results by showing the humanizing effect of imagined contact on usually mechanized target. This study demonstrated that people who imagined interacting with a 
Japanese person expressed reduced mechanistic dehumanization, that is increased attribution of human nature traits. Moreover, imagined contact enhanced support for human rights of Japanese people and this effect was explained by increased humanization of them. This evidence further enhances the validity of Study 2 results.

\section{General Discussion}

Across three studies we found support for the humanizing consequences of imagined contact. Moreover, we provided consistent evidence for humanization as a mediator of the effects of imagined contact. People attribute more uniquely human characteristics (both traits and expression of secondary emotions) to Gypsies and this in turn promotes the tendency to respect Gypsy human rights after imagined contact. Similarly, people attribute more human nature traits to Japanese people and this increases the support for Japanese people's human rights.

Our research is the first to find that imagined contact improve outgroup members' humanization in adults, as it does in children (Vezzali et al., 2012; Vezzali et al., 2011). Importantly, we considered not only marginalized minorities or low status groups as in previous studies, but also a high status group such as Japanese people extending the impact of imagined contact intervention to reduced prejudice towards these groups. This implies that imagined contact extends the circle of human concern to others independent of the status or power interrelation between perceivers and target group. This strategy then can be applied in multiple contexts to improve intergroup relationships and it does so in a rather stable way that is not by increasing others' pleasantness but by increasing the perception of them as human beings with our same human rights. 
Previous research has shown that multiple and counter-stereotypic categorizations are effective interventions to promote the humanization of outgroup targets (Prati, Crisp, Meleady, \& Rubini, 2016; Prati, Crisp, \& Rubini, 2015; Prati et al., 2015). However, prior research has been insensitive to the specific type of humanness the target is usually denied. In this regard, the present research revealed that imagined contact does not simply increase all humanness; it appears to specifically work at increasing the type of humanness the group is typically denied.

Many groups are dehumanized, treated unequally, and suffer as a result (Costello \& Hodson, 2010; Cuddy et al., 2007; Struch \& Schwartz, 1989; Vaes \& Paladino, 2010). Our research demonstrates how this might be counteracted. Imagined contact reflects only one technique, and is arguably the weakest means of reducing prejudice through contact. That the current research detected a significant increase in humanization indicates that extended or actual contact may have similar or greater effects. In this vein, imagined contact is useful as a pre-contact tool, so as to encourage people to approach outgroup members with positive intentions (Crisp et al., 2010a).

This research has some limitations. We acknowledge the low reliability of well-established measures of dehumanization, such as the attribution of primary emotions. Even if this may have affected the reliability of individual results, the findings on this measure were consistent across the three studies. Further, this was only one of the two measures of dehumanization that we used in these studies, and it was the second measure (human traits) which was used to assess the mediating role of humanization on the effects of imagined contact. Moreover, further studies should consider a neutral control condition in order to obtain stronger effects of the manipulation. It is possible that the use of a control condition concerning a positive context may have elicited positive attitudes that 
undermine the positive effects of imagined contact. At the same time, this further highlights the strength of our evidence. Finally, across the studies some of the mean levels of humanness in the control condition are not below the midpoint of the scale, indicating that in the control condition there is no dehumanization. Nevertheless, this highlights that imagined contact does not reduce dehumanization and simply stop once the midpoint is reached, rather it improves the specific attribution of humanness that groups are perceived to lack.

In conclusion, this research indicates that despite being pervasive at both intergroup and interpersonal level, dehumanization can be reduced. The findings offer imagined contact as a path to improve social integration in increasingly multicultural but still segregated societies through undermining outgroup dehumanization.

\section{References}

Abrams, D., Crisp, R. J., Marques, S., Fagg, E., Bedford, L., \& Provias, D. (2009). Threat inoculation: Experienced and imagined intergenerational contact prevents stereotype threat effects on older people's math performance. Psychology and Aging, 23, 934-939.

Allport G. W. (1954). The nature of prejudice. Cambridge, MA: Addison-Wesley.

Andrighetto, L., Baldissarri, C., Lattanzio, S., Loughnan, S., \& Volpato, C. (2014). Human-itarian aid? Two forms of dehumanization and willingness to help after natural disasters. British Journal of Social Psychology, 53, 573-584.

Aron, A., Aron, E. N., \& Smollan, D. (1992). Inclusion of other in the self-scale and the structure of interpersonal closeness. Journal of Personality and Social Psychology, 63, 596-612. 
Bain, P., Park, J., Kwok, C., \& Haslam, N. (2009). Attributing human uniqueness and human nature to cultural groups: Distinct forms of subtle dehumanization. Group Processes \& Intergroup Relations, 12, 789-805.

Bandura, A. (1996). Failures in self-regulation: Energy depletion or selective disengagement? Psychological Inquiry, 7, 20-24.

Bar-Tal, D. (1990). Causes and consequences of delegitimization: Models of conflict and ethnocentrism. Journal of Social Issues, 46, 65-81.

Bastian, B., \& Haslam, N. (2010). Excluded from humanity: Ostracism and dehumanization. Journal of Experimental Social Psychology, 46, 107-113.

Bastian, B., Jetten, J., \& Radke, H. R. (2012). Cyber-dehumanization: Violent video game play diminishes our humanity. Journal of Experimental Social Psychology, 48, 486-491.

Birtel, M. D., \& Crisp, R. J. (2012). "Treating" prejudice: An exposure-therapy approach to reducing negative reactions toward stigmatized groups. Psychological Science, 23, 13791386.

Brambilla, M., Ravenna, M., \& Hewstone, M. (2012). Changing stereotype content through mental imagery: Imagining intergroup contact promotes stereotype change. Group Processes \& Intergroup Relations, 15, 305-315.

Brent, J. (2004). The desire for community: Illusion, confusion and paradox. Community Development Journal, 39, 213-23. 
Brown, R., Eller, A., Leeds, S., \& Stace, K. (2007). Intergroup contact and intergroup attitudes: A longitudinal study. European Journal of Social Psychology, 37, 692-703.

Brown, R., \& Hewstone, M. (2005). An integrative theory of intergroup contact. Advances in Experimental Social Psychology, 37, 255-343.

Cameron, L., Rutland, A., Turner, R., Holman-Nicolas, R., \& Powell, C. (2011). 'Changing attitudes with a little imagination': Imagined contact effects on young children's intergroup bias. Anales De Psicologia, 27, 708-717.

Capozza, D., Trifiletti, E., Vezzali, L., \& Favara, I. (2013). Can intergroup contact improve humanity attributions?. International Journal of Psychology,48, 527-541.

Chulvi, B., \& Pérez, J.A. (2005). El prejuicio genealògico. Psicologia Politica, 30, 57-70.

Costello, K., \& Hodson, G. (2010). Exploring the roots of dehumanization: The role of animal human similarity in promoting immigrant dehumanization. Group Processes and Intergroup Relations, 13, 3-22.

Commission for Racial Equality (CRE), (2004). Gypsies and Travellers: A Strategy for the CRE 2004-2007, Commission for Racial Equity.

Crisp, R. J., Stathi, S., Turner, R. N., \& Husnu, S. (2009). Imagined intergroup contact: Theory, paradigm and practice. Social and Personality Psychology Compass, 3, 1-18.

Crisp, R. J., \& Turner, R. N. (2009). Can imagined interactions produce positive perceptions? Reducing prejudice through simulated social contact. American Psychologist, 64, 231-240. 
Cuddy, A., Rock, M.S., \& Norton, M.I. (2007). Aid in the aftermath of hurricane Katrina: Inferences of secondary emotions and intergroup helping. Group Processes and Intergroup Relations, 10, 107-118.

Dadds, M. R., Bovbjerg, D. H., Redd, W. H., \& Cutmore, T. R. (1997). Imagery in human classical conditioning. Psychological Bulletin, 122, 89-103.

Demoulin, S., Leyens, J. Ph., Paladino, M. P., Rodriguez, R. T., Rodriguez, A. P., \& Dovidio, J. F. (2004). Dimensions of "uniquely" and "non-uniquely" emotions. Cognition and Emotion, $18,71-96$.

European Commission, (2011). 'Communication from the Commission to the European Parliament, The Council, The European Economic and Social Committee and the Committee of the Regions - An EU Framework for National Roma Integration Strategies up to 2020’.

Fiske, S. T., Cuddy, A. J., Glick, P., \& Xu, J. (2002). A model of (often mixed) stereotype content: competence and warmth respectively follow from perceived status and competition. Journal of Personality and Social Psychology, 82, 878-902.

Garcia, S. M., Weaver, K., Moskowitz, G. B., \& Darley, J. M. (2002). Crowded minds: the implicit bystander effect. Journal of Personality and Social Psychology, 83, 843-853.

Greenland, K., \& Brown, R. (1999). Categorization and intergroup anxiety in contact between British and Japanese nationals. European Journal of Social Psychology, 29, 503-521. Greitemeyer, T., \& McLatchie, N. (2011). Denying humanness to others: A newly discovered mechanism by which violent video games increase aggressive behavior. Psychological Science, 22, 659-665. 
Haslam, N. (2006). Dehumanization: An integrative review. Personality and Social Psychology Review, 10, 252-264.

Haslam, N. \& Bain, P. (2007). Humanizing the self: Moderators of the attribution of lesser humanness to others. Personality and Social Psychology Bulletin, 33, 57-68.

Haslam, N., Bain, P., Douge, L., Lee, M., \& Bastian, B. (2005). More human than you: Attributing humanness to self and others. Journal of Personality and Social Psychology, 89, 973-950.

Haslam, N., \& Loughnan, S. (2014). Dehumanization and infrahumanization. Annual Review of Psychology, 65, 399-423.

Heflick, N. A., \& Goldenberg, J. L. (2009). Objectifying Sarah Palin: Evidence that objectification causes women to be perceived as less competent and less fully human. Journal of Experimental Social Psychology, 45, 598-601.

Husnu, S., \& Crisp, R. J. (2010a). Elaboration enhances the imagined contact effect. Journal of Experimental Social Psychology, 46, 943-950.

Husnu, S., \& Crisp, R. J. (2010b). Imagined Intergroup Contact: A New Technique for Encouraging Greater Inter-Ethnic Contact in Cyprus. Peace and Conflict: Journal of Peace Psychology, 16, 97-108.

Katz, D., \& Braly, K. (1933). Racial stereotypes of one hundred college students. The Journal of Abnormal and Social Psychology, 28, 280-290.

Kelman, H. C. (1973). Violence without moral restraint: Reflections on the dehumanization of victims and victimizers. Journal of Social Issues, 23, 25-61. 
Kelso, M. (1999). Gypsy deportations from Romania to Transnistria 1942-44. In: Kenrick, D. (ed.) In the Shadow of the Swastika. The Gypsies during the Second World War - 2. Hatfield: University of Hertfordshire Press, 95-130.

Lemmer, G., \& Wagner, U. (2015). Can we really reduce ethnic prejudice outside the lab? A meta-analysis of direct and indirect contact interventions. European Journal of Social Psychology, 45, 152-168.

Leyens, J. Ph., Demoulin, S., Vaes, J., Gaunt, R., Paladino, M. P. (2007). Infra-humanization: The wall of group differences. Social Issues and Policy Review, 1, 139-172.

Leyens, J. Ph., Paladino, M. P., Rodriguez, R. T., Vaes, J., Demoulin, S., Rodriguez, A. P., et al. (2000). The emotional side of prejudice: The role of secondary emotions. Personality and Social Psychology Review, 4, 186-197.

Leyens, J.-P., Rodriguez-Perez, A., Rodriguez-Torres, R., Gaunt, R., Paladino, M.P., Vaes, J., \& Demoulin, S. (2001). Psychological essentialism and the differential attribution of uniquely human emotions to ingroups and outgroups. European Journal of Social Psychology, 31, $395-411$.

Lin, M. H., Kwan, V. S. Y., Cheung, A.,\& Fiske, S. T. (2005). Stereotype Content Model Explains Prejudice for an Envied Outgroup: Scale of Anti-Asian American Stereotypes. Personality and Social Psychology Bulletin, 31, 34-47.

Loughnan, S., \& Haslam, N. (2007). Animals and androids: Implicit associations between social categories and nonhumans. Psychological Science, 18, $116-121$. 
Loughnan, S., Haslam, N., \& Kashima, Y. (2009). Understanding the relationship between attribute-based and metaphor-based dehumanization. Group Processes and Intergroup Relations, 12, 747-762.

Loughnan, S., B. Leidner, G. Doron, N. Haslam, Y. Kashima, J. Tong and V. Yeung. (2010). Universal biases in self-perception: Better and more human than average. British Journal Social Psychology, 49, 627-636.

Mackie, D. M., Devos, T., \& Smith, E. R. (2000). Intergroup emotions: explaining offensive action tendencies in an intergroup context. Journal of Personality and Social Psychology, 79, 602616.

Marcu, A., \& Chryssochoou, X. (2005). Exclusion of ethnic groups from the realm of humanity: Prejudice against the Gypsies in Britain and in Romania. Psicologia Politica, 30, 41-56. Opotow, S. (1990). Deterring moral exclusion. Journal of Social Issues, 46, 173-182.

Pagotto, L., Visintin, E. P., De Iorio, G., \& Voci, A. (2012). Group Processes \& Intergroup. Group Processes \& Intergroup Relations, 16, 209-216.

Paolini, S., Harwood, J., \& Rubin, M. (2010). Negative intergroup contact makes group memberships salient: Explaining why intergroup conflict endures. Personality and Social Psychology Bulletin, 36, 1723-1738.

Pérez, J. A., Chulvi, B., \& Alonso, R. (2001). When a majority fails to convert a minority: The case of Gypsies. In F. Butera, \& G. Mugny (Eds.), Social influence in social reality. Seattle: Hogrefe and Huber Publishers, 143-164. 
Prati, F., Crisp, J.R., Meleady, R., Rubini, M. (2016). Humanizing Outgroups through Multiple Categorization: The Roles of Individuation and Threat. Personality \& Social Psychology Bulletin, 42, 526-539.

Prati, F., Crisp J.R., \& Rubini, M. (2015). Counter-stereotypes reduce emotional intergroup bias by eliciting surprise in the face of unexpected category combinations. Journal of Experimental Social Psychology, 61, 31-43.

Prati, F., Vasiljevic, M., Crisp, J. R., \& Rubini, M. (2015). Some extended psychological benefits of challenging social stereotypes: Decreased dehumanization and a reduced reliance on heuristic thinking. Group Processes \& Intergroup Relations, 18, 801-816.

Preacher, K. J., \& Hayes, A. F. (2008). Asymptotic and re-sampling strategies for assessing and comparing indirect effects in multiple mediator models. Behavior Research Methods, 40, $879-891$.

Saminaden, A., Loughnan, S., \& Haslam, N. (2010). Afterimages of savages: Implicit associations between primitives, animals and children. British Journal of Social Psychology, 49, 91-105.

Stathi, S. \& Crisp, R. J. (2008). Imagining intergroup contact promotes projection to outgroups. Journal of Experimental Social Psychology, 44, 943-957.

Stathi, S., Crisp, R. J., \& Hogg, M. A. (2011). Imagining intergroup contact enables member-togroup generalization. Group Dynamics: Theory, Research, and Practice, 15, 275-284.

Stathi, S., Tsantila, K., \& Crisp, R. J. (2012). Imagining Intergroup Contact Can Combat Mental Health Stigma by Reducing Anxiety, Avoidance and Negative Stereotyping. Journal of Social Psychology, 152, 746-757.

This article is protected by copyright. All rights reserved. 
Staub, E. (1989). The roots of evil: Psychological and cultural origins of genocide and other group violence. New York: Cambridge University Press.

Stonewall. (2003). Profiles of prejudice: The nature of prejudice in England: in-depth analysis of findings carried out by MORI in May 2003 on behalf of Stonewall's Citizenship 21 project. London: Stonewall.

Struch, N., \& Schwartz, S. H. (1989). Intergroup aggression: Its predictors and distinctness from ingroup bias. Journal of Personality and Social Psychology, 56, 364-373.

Tam, T., Hewstone, M., Cairns, E., Tausch, N., Maio, G., \& Kenworthy, J. (2007). The impact of intergroup emotions on forgiveness in Northern Ireland. Group Processes \& Intergroup Relations, 10, 119-136.

Turner, R.N. \& Crisp, R. J. (2010). Imagining intergroup contact reduces implicit prejudice. British Journal of Social Psychology, 49, 1, 129-142.

Turner, R. N., Crisp, R. J., \& Lambert, E. (2007). Imagining intergroup contact can improve intergroup attitudes. Group Processes and Intergroup Relations, 10, 427-441.

Twelvetrees, A. (2002) Community Work. Basingstoke: Macmillan.

Vaes, J., \& Paladino, M.P. (2010). The uniquely human content of stereotypes. Group Processes and Intergroup Relations, 13, 23-39.

Vaes, J., Paladino, M.P., Castelli, L., Leyens. J.P., \& Giovanazzi, A. (2003). On the behavioral consequences of infrahumanization: The implicit role of uniquely human emotions in intergroup relationships. Journal of Personality and Social Psychology, 85, 1016-1034. 
Valentine, G. \& McDonald, I. (2004) Understanding Prejudice: Attitudes Towards Minorities. London: Stonewall.

Vezzali, L., Capozza, D., Giovannini, D., \& Stathi, S. (2012). Improving implicit and explicit intergroup attitudes using imagined contact: An experimental intervention with elementary school children. Group Processes \& Intergroup Relations, 15, 203-212.

Vezzali, L., Capozza, D., Stathi, S., \& Giovannini, D. (2012). Increasing outgroup trust, reducing infrahumanization, and enhancing future contact intentions via imagined intergroup contact. Journal of Experimental Social Psychology, 48, 437-440.

Viki, G. T., Winchester, L., Titshall, L., Chisango, T., Pina, A., \& Russell, R. (2006). Beyond secondary emotions: The infrahumanization of outgroups using human-related and animalrelated words. Social Cognition, 24, 753-775.

West, K., Holmes, E., \& Hewstone, M. (2011). Enhancing imagined contact to reduce prejudice against people with schizophrenia. Group Processes \& Intergroup Relations, 14, 407-428.

This article is protected by copyright. All rights reserved. 


\section{Footnotes}

${ }^{1}$ Given that both groups are known as 'gypsies', we will use this term to refer to Roma and Traveller populations collectively unless otherwise specified.

${ }^{2}$ A final task was included in the questionnaire the graphical measure of Inclusion of Others in the Self used by Aron, Aron and Smollan (1992). We adapted this measure to assess participants' perceived closeness between Gypsies and the human group. This measure consisted of seven pairs of circles each one composed of a small circle representing the target group and a large circle representing the human group. Each pair presents a different degree of overlap between the two circles, from completely separate (coded 1) to concentric (coded 7). Participants chose the pair of circles that best represented the level of inclusion between Gypsies and the human group. As expected, participants in the imagined contact condition saw significantly more overlap compared to those in the control condition, $F(1,89)=28.755, p=.001, \eta^{2}=.244$. In line with other results, this measure showed that participants tended to include Gypsies in the human group to a greater extent after imagined contact. Although this yielded convergent evidence, the high face validity of this measure may have revealed the hypothesis of the study to participants, and therefore it was excluded from the other studies.

${ }^{3}$ The item 'marry the woman/man who they want' was removed to improve the reliability of the human rights scale from .61 to .65 , and the mean results were not altered. 


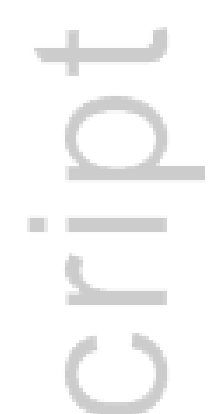

Table 1. Means, standard deviations as a function of condition and Pearson's correlations between all measures (Study 1).

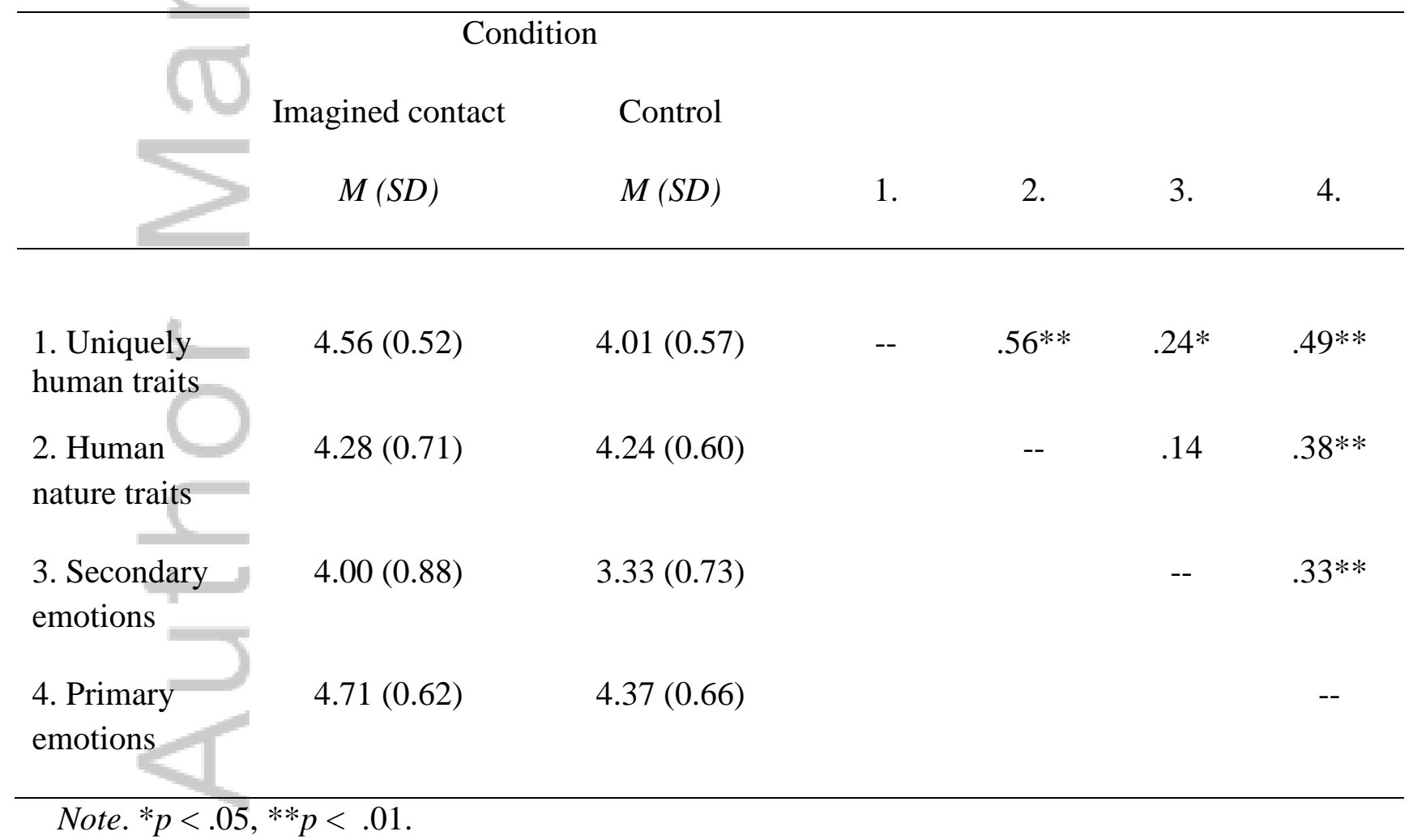


Note. Scale anchors range from 1(much less than average population/not at all) to 7 (much more than average population/very much).

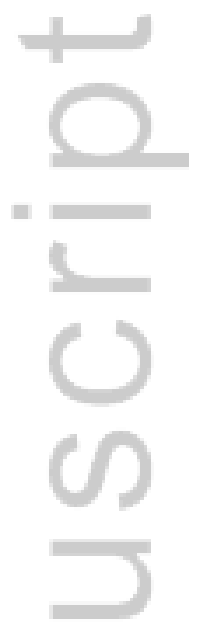

Table 2. Means, standard deviations as a function of condition and Pearson's correlations between all measures (Study 2).

\begin{tabular}{|c|c|c|c|c|c|c|c|c|c|}
\hline \multicolumn{10}{|c|}{ Condition } \\
\hline & Imagined & Control & & & & & & & \\
\hline & $M(S D)$ & $M(S D)$ & 1. & 2. & 3. & 4. & 5. & 6. & 7. \\
\hline 4 & & & & & & & & & \\
\hline $\begin{array}{l}\text { 1. Uniquely human } \\
\text { traits }\end{array}$ & $4.72(1.06)$ & $3.78(1.08)$ & -- & $.61 * *$ & $.32 *$ & -.04 & .20 & $.28 *$ & $.44^{* *}$ \\
\hline $\begin{array}{l}\text { 2. Human nature } \\
\text { traits }\end{array}$ & $4.50(0.77)$ & $4.05(0.72)$ & & -- & $.37 * *$ & .20 & .25 & -.15 & $.30 *$ \\
\hline
\end{tabular}




\begin{tabular}{|c|c|c|c|c|c|c|}
\hline $\begin{array}{l}\text { 3. Secondary } \\
\text { emotions }\end{array}$ & $4.45(0.72)$ & $4.01(0.60)$ & $--\quad .56^{* *}$ & .23 & .04 & $.46^{* *}$ \\
\hline $\begin{array}{l}\text { 4. Primary } \\
\text { emotions }\end{array}$ & $4.35(0.87)$ & $4.26(0.72)$ & -- & $.31 *$ & -.08 & .32 \\
\hline $\begin{array}{l}\text { 5. Positive } \\
\text { behavioural } \\
\text { intentions }\end{array}$ & $4.01(1.26)$ & $4.00(1.45)$ & & -- & -.16 & $.40 * *$ \\
\hline $\begin{array}{l}\text { 6. Negative } \\
\text { behavioural } \\
\text { intentions }\end{array}$ & $1.98(0.57)$ & $2.84(0.58)$ & & & -- & $-.34 *$ \\
\hline 7. Human rights & $5.56(0.89)$ & $4.95(1.21)$ & & & & -- \\
\hline
\end{tabular}

Note. Scale anchors range from 1(much less than average population/not at all) to 7 (much more than average population/very much).

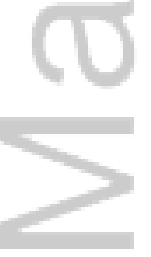

Table 3. Means, standard deviations as a function of condition and Pearson's correlations between all measures (Study 3).

\begin{tabular}{|c|c|c|c|c|c|c|c|}
\hline \multirow[t]{3}{*}{$\sqrt{4-5}$} & \multicolumn{2}{|c|}{ Condition } & & & & & \\
\hline & Imagined contact & Control & & & & & \\
\hline & $M(S D)$ & $M(S D)$ & 1. & 2. & 3. & 4. & 5. \\
\hline
\end{tabular}




\begin{tabular}{|c|c|c|c|c|c|c|c|}
\hline $\begin{array}{l}\text { 1.Uniquely } \\
\text { human traits }\end{array}$ & $4.40(0.79)$ & $4.12(1.09)$ & -- & .07 & .05 & -.06 & .13 \\
\hline $\begin{array}{l}\text { 2. Human } \\
\text { nature traits }\end{array}$ & $4.51(0.83)$ & $3.18(0.71)$ & & -- & $.25^{*}$ & -.15 & $.45 * *$ \\
\hline $\begin{array}{l}\text { 3. Secondary } \\
\text { emotions }\end{array}$ & $4.32(0.89)$ & $4.13(0.86)$ & & & -- & -.11 & $.30 *$ \\
\hline $\begin{array}{l}\text { 4. Primary } \\
\text { emotions }\end{array}$ & $4.38(1.12)$ & $3.83(1.13)$ & & & & -- & -.14 \\
\hline $\begin{array}{l}\text { 5. Human } \\
\text { rights }\end{array}$ & $3.40(1.47)$ & $2.12(0.96)$ & & & & & -- \\
\hline
\end{tabular}

Note. ${ }^{*} p<.05, * * p<.01$.

Note. Scale anchors range from 1(much less than average population/not at all) to 7 (much more than average population/very much).

Figure captions

This article is protected by copyright. All rights reserved. 
Figure 1. The mediating role of human uniqueness in the relationship between imagined contact with a Gypsy person and human rights.

Figure 2. The mediating role of human nature in the relationship between imagined contact with a Japanese person and human rights.

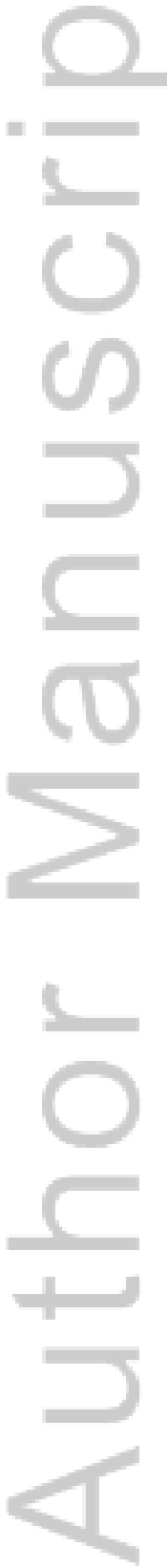

This article is protected by copyright. All rights reserved. 
Imagine People Like Us: Imagined Intergroup Contact Promotes Support for Human Rights through Increased Humanization

\section{Corresponding Author: Francesca Prati}

University of Bologna Bologna Italy

Email Add: francesca.prati@unibo.it

Alternate email Add: franklinfelixp@gmail.com

\section{Author: Steve Loughnan}

University of Edinburgh Edinburgh Edinburgh United Kingdom Edinburgh

Email Add:steve.loughnan@ed.ac.uk

This article is protected by copyright. All rights reserved. 


\section{University Library}

\section{- $\mathrm{M}$ IIN E R VA A gateway to Melbourne's research publications}

Minerva Access is the Institutional Repository of The University of Melbourne

Author/s:

Prati, F;Loughnan, S

Title:

Imagined intergroup contact promotes support for human rights through increased humanization

Date:

2018-02-01

\section{Citation:}

Prati, F. \& Loughnan, S. (2018). Imagined intergroup contact promotes support for human rights through increased humanization. European Journal of Social Psychology, 48 (1), pp.051-O61. https://doi.org/10.1002/ejsp.2282.

Persistent Link:

http://hdl.handle.net/11343/293161 